\title{
Oral citicoline: Influence of long-term therapy on perimetric glaucoma defects
}

\author{
Journal: Panminerva Medica \\ Paper code: Panminerva Med-4005 \\ Submission date: June 8, 2020 \\ Article type: Letter to the Editor
}

Files:

1. Reply letter to comments on the manuscript

Version: 1

Description:

File format: application/vnd.openxmlformats-officedocument.wordprocessingml.document

2. Manuscript

Version: 6

Description: Manuscript

File format: application/vnd.openxmlformats-officedocument.wordprocessingml.document

3. Figures 12

Version: 1

Description: Figure 1 - Mean Deviation (MD) trend as a function of time (Times 0, and 12, 24, and 36 months) and therapy.

File format: application/pdf

4. Figures 13

Version: 1

Description: Figure 2 - Pattern standard deviation (PSD) trend as a function of time (Times 0 , and 12,24 , and 36 months) and therapy.

File format: application/pdf

5. Figures 14

Version: 1

Description: Figure 3 - Glaucoma Staging System 2 (GSS2) stage trend as a function of time (Times 0 , and 12, 24, and 36 months) and therapy.

File format: application/pdf 


\section{Panminerva Medica \\ EDIZIONI MINERVA MEDICA}

6. Figures 15

Version: 1

Description: Figure 4 - Best-corrected visual acuity (BVCA) as a function of time (Times 0, and 12, 24, and 36 months) and therapy.

File format: application/pdf

7. Figures 16

Version: 1

Description: Figure 5 - Mean intraocular pressure (IOP) trend as a function of time (Times 0 , and 12,24 , and 36 months) and therapy.

File format: application/pdf

8. Supplementary Digital Material 1

Version: 1

Description: tables

File format: application/vnd.openxmlformats-officedocument.wordprocessingml.document 
Dear Editor-in-Chief Prof. Benzo:

2

3

4

5

6

The manuscript "Oral citicoline: Influence of long-term therapy on perimetric glaucoma defects" is being resubmitted as "letter to the Editor", as requested by the journal.

Thank you for your consideration.

We look forward to hearing from you.

Best Regards

Prof. Elena Pacella
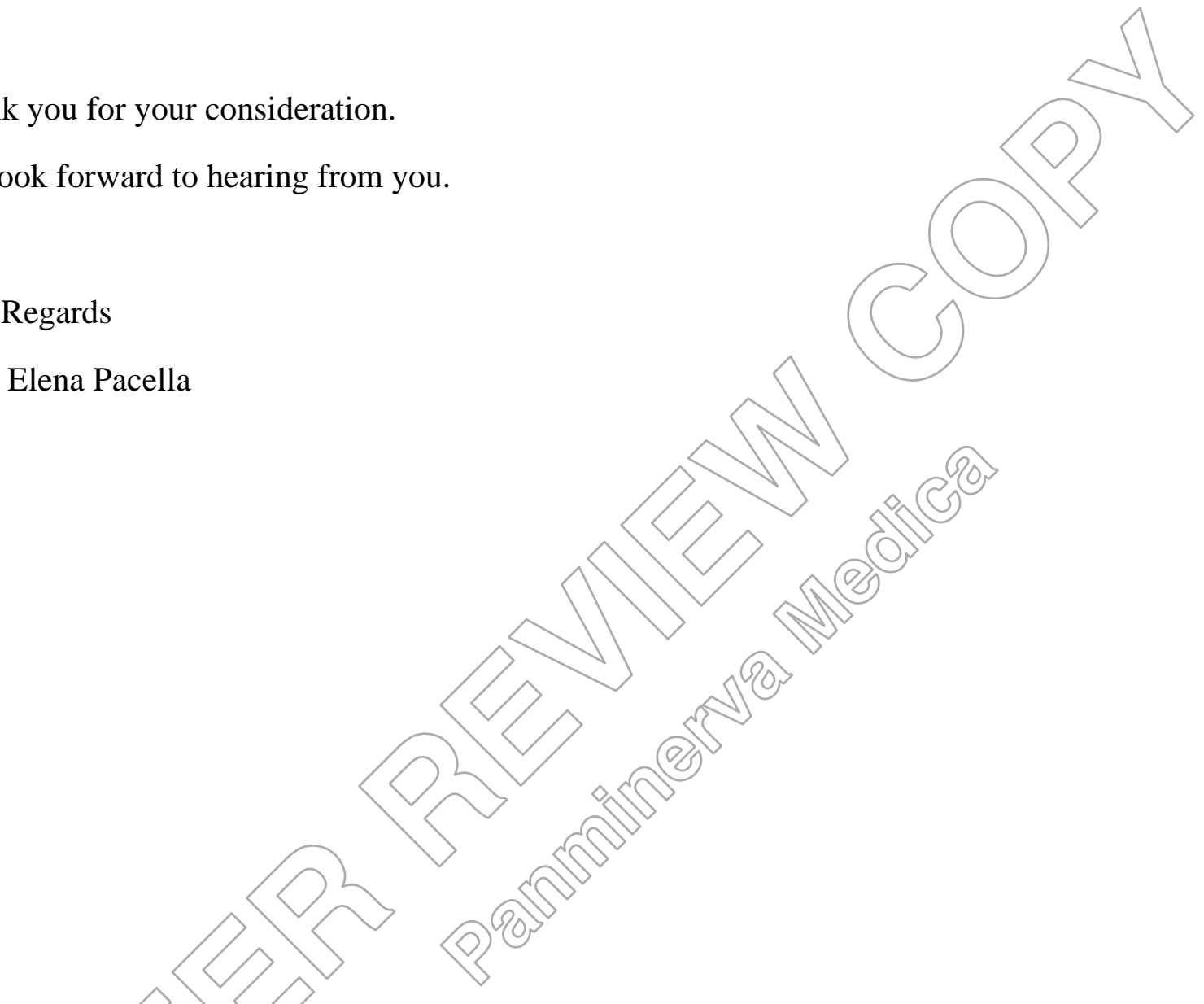


\section{Title: Oral Citicoline: Influence of long-term therapy on perimetric glaucoma defects}

Running title: long-term therapy with Citicoline and perimetric defects

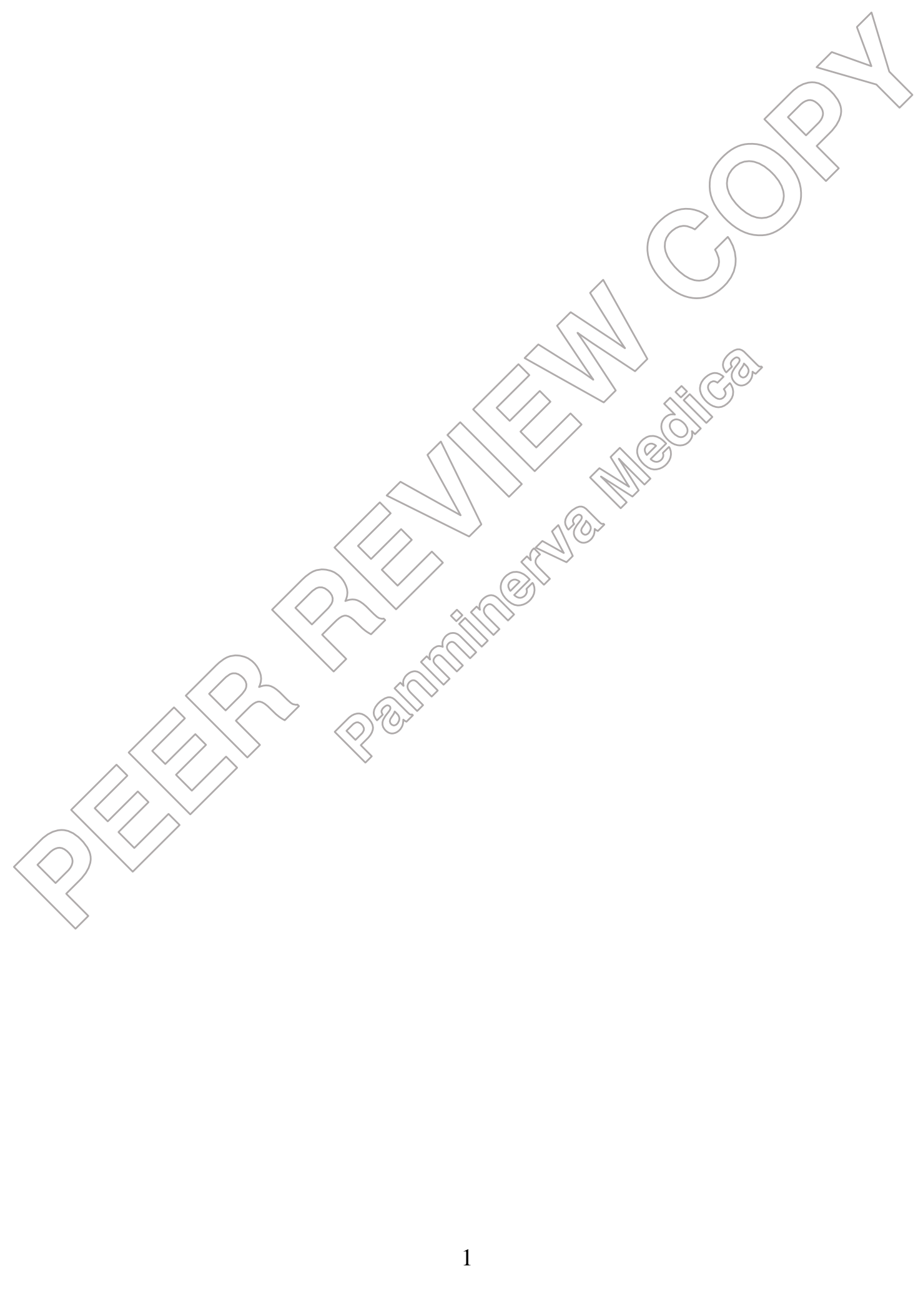


Authors

L. Arrico ${ }^{1}$, S. Compagno ${ }^{1}$, F. Pacella ${ }^{1}$, D. Bianchini ${ }^{1}$, C. Borrazzo ${ }^{2}$, P. Turchetti ${ }^{3}$, M. Malvasi ${ }^{1}$, E. Trovato Battagliola ${ }^{1}$, E. Pacella ${ }^{1 *}$

1. Glaucoma Service Eye Clinic, Department of Sense Organs, Sapienza University of Rome Italy.

2. Statistics Unit, Department of Public Health and Infectious Diseases, Sapienza Uniyersity of Rome Italy.

3. National Institute for Health, Migration and Poverty (INMP/NIHMP), Rome, Italy.

*Correspondence: Prof. Elena Pacella MD-PhD

Department of Sense Organs

University of Rome "La Sapienza"

Via del Policlinico 155, 00161 Rome, Italy

Tel +39336783409 Fax +390649975304

Email: elena.pacella@uniroma1.it

Keywords: Citicoline; Oral Therapy; Perimetric Glaucoma Defects; POAG; Visual Field

Authors received no funding for this study

Authors decline any financial interest 
To the Editor:

Primary Open Angle Glaucoma (POAG) is characterized by a gradual loss of retinal ganglion cells (RGCs). Visual impairment ranges from visual field defects to blindness. Intraocular pressure (IOP) is the primary risk factor for POAG progression $[1,2]$. However, recent studies suggest that therapy cannot be limited to IOP lowering alone. In fact, despite adequate IOP control, the disease still progresses in a percentage of patients [3]. In these, vascular or mechanical neurodegenerative processes are likely responsible. Therefore, the current trend is to prescribe molecules capable of inhibiting RGCs apoptosis. Citicoline, also known as choline CDP, is an endogenous organic neuroprotective molecule and acts as an intermediary in phosphatidyicholine synthesis. Growing evidence suggests that it stimulates neural cell metabolism, inhibits phospholipids degradation, and possibly even apoptosis. [4]. For this purpose, authors performed a retrospective study to explore the effect of citicoline supplementation on visual field defects progression.

The study recruited 60 subjects with PQAG (33) males, 27 fernales; average age: 69.2 years; minimum age: 44 years; maximum age: 86 years). These were ail 4th stage POAG on the GGS2 classification system. A third group of 30 healthy subjects was included as control (Healthy Group - HG). HG subjects did not suffer from ocular diseases or systemic comorbidities (hypertension or diabetes mellitus, among gthers), and their visual fields were normal. All three groups were comparable for age and gender. Inclusion criteria: POAG (IV grade on the Shaffer classification); IOP effectively controlled with hypotensive therapy $(<18 \mathrm{mmHg})$; corneal pachymetry within the following range: $>$ $520 \mu \mathrm{m}$ and $<550 \mu \mathrm{m}$. Exclusion criteria: ocular pathologies other than POAG; opacities of the dioptric mediums. POAG subjects were divided in two groups: Therapy Group (TG) received oral citicoline plus conventional hypotensive therapy. Oral $500 \mathrm{mg}$ citicoline was prescribed daily for two consecutive months, then suspended for one month. The Control Group (CG) received hypotensive therapy alone. Perimetry using the Humphrey Perimeter (Humphrey program 30-2 HFA II and SITA 
Standard threshold strategy) was obtained from each participant at baseline as well as 12, 24, and 36 months post enrollment. Outcome measures included: Mean Deviation (MD) and Pattern Standard Deviation (PSD) values on perimetry testing, best corrected visual acuity (BVCA), POAG stage (Glaucoma Staging System 2), and IOP. Groups were compared using the Student's t test for paired samples. The computations were made using the SPSS software v. 22.0 for Microsoft Windows. Statistical significance was set at $\mathrm{P}<0.05$. This study was approved by the Institutional Review Board of La Sapienza University of Rome (Protocol No. 1076/14). All participants signed a written consent form upon enrollment. This study was performed in accordance with the tenets of the Declaration of Helsinki.

As shown in Figures 1 and 2 and Tables I - IV, TG subjects showed @statistically significant improvement in both the mean MD and mean PSD scores, when comparing T0 with T36 $(\mathrm{P}=0.001)$. No statistically significant changes in the mean MD and PSB scores were noted in the other two groups ( $\mathrm{P}>0.05)$. Figure 3, Tables $\mathrm{V}$ and indicate a shift of the mean GSS 2 Stage towards better values among TG subjects, when comparing T0 and $136(\mathrm{P}=0.001)$. No statistically significant changes in the mean GSS 2 Stage were noted among CG or HG $(\mathrm{P}>0.05)$. Figure 4 shows that TG subjects showed an improvement in BGVA $(\mathrm{P}<0.05)$. CG subjects did not. Figure 5 shows mean IOP values. Al the recorded IOP values were below $18 \mathrm{mmHg}$. This indicates adequate IOP control. IOP fluctuations were not statistically significant.

The increase of MD score towards less negative values and the reduction of the PSD score indicate an improvement in retinal sensitivity at follow-up visual field testing [5]. Conversely, a decrease of the MD score towards more negative values and the increase of the PSD score indicate the opposite, that is a decrease in retinal sensitivity secondary to RGC loss (Figures 1 and 2). As previously mentioned, POAG progresses in a subset of patients despite adequate IOP control. Recent studies have explored the role of citicoline in halting disease progression in this subset of patients. Citicoline 
has been shown to improve retinal sensitivity, PERG and PEV parameters, and reduce scotoma expansion [4].

In the present study, oral administration of citicoline led to a significant improvement in the perimetry indices in TG subjects. Changes equated to a 35\% increase (less negative) in the mean MD score and a $16 \%$ decrease in the mean PSD score, when comparing T0 with T36. This indicates a statistically significant improvement $(\mathrm{p}$-value $=0.001)$ of the retinal sensitivities (Figure 4$)$. On the contrary, CG subjects showed a decrease towards more negative values of the mean MD score and an increase of the mean PSD score, but this change was not statistically significant $(\mathrm{P}>0.05)$. Progression of the MD score towards more negative values and progression of the PSD score towards more positive values is indicative of visual field defects progression. These results suggest the potential role of using citicoline in addition to hypotensive therapy to halt POAG disease progression.

In summary, the therapeutic association with oral $500 \mathrm{mg}$ citieoline assumed daily has shown a promising neuroprotective effect on RGCs. 
1 Abbreviations found in this article:

2 3 4

POAG: Primary Open-Angle Glaucoma

RGCs: Retinal Ganglion Cells

IOP: Intraocular Pressure

MD: Mean Deviation

PSD: Pattern Standard Deviation

GSS2: Glaucoma Staging System 2

TG: Therapy Group

CG: Control Group

HG: Healthy Group 
5

6 7 8

Table I: Comparison of Median Deviation (MD) scores between groups: Control, Health, and Therapy. The table shows the mean \pm standard deviation (SD).

\begin{tabular}{|c|c|c|c|c|}
\hline MD score & $\begin{array}{c}\text { T0 } \\
\text { (mean } \pm \text { SD) }\end{array}$ & $\begin{array}{c}\text { T12 } \\
\text { (mean } \pm \text { SD) }\end{array}$ & $\begin{array}{c}\text { T24 } \\
\text { (mean } \pm \text { SD) }\end{array}$ & $\begin{array}{c}\text { T36 } \\
\text { (mean } \pm \text { SD) }\end{array}$ \\
\hline Control Group & $-14 \pm 6.1$ & $-14 \pm 3.9$ & $-15 \pm 4$ \\
\hline Healthy Group & $0.1 \pm 1$ & $0.2 \pm 1.1$ & $0.2 \pm 0.7$ \\
\hline Therapy Group & $-14 \pm 3.2$ & $-11 \pm 2.4$ & $-9 \pm 4$ \\
\hline
\end{tabular}


6

7

8

Table II: Relative change in the Median Deviation score for each group, as compared to previous value. Student's t test for paired samples. (*). P value > 0.05 is statistically significant.

\begin{tabular}{|c|c|c|c|c|c|c|}
\hline MD score & $\begin{array}{c}\text { T0- T12 } \\
(\boldsymbol{\Delta})\end{array}$ & $\mathbf{p}$-value & $\begin{array}{c}\text { T0- T24 } \\
(\boldsymbol{\Delta})\end{array}$ & p-value & $\begin{array}{c}\text { T0- T36 } \\
(\boldsymbol{\Delta})\end{array}$ & p-value \\
\hline Control Group & $-7 \%$ & 0.151 & $-6 \%$ & 0.211 & $-7 \%$ & 0.151 \\
\hline Healthy Group & $<1 \%$ & 0.333 & $<1 \%$ & 0.353 & $<1 \%$ & 0.233 \\
\hline Therapy Group & $+21 \%$ & $\mathbf{0 . 0 0 1}(*)$ & $+35 \%$ & $\mathbf{0 . 0 0 1}\left({ }^{*}\right)$ & $+35 \%$ & $\mathbf{0 . 0 0 1}(*)$ \\
\hline
\end{tabular}


Table III: Comparison of Pattern Standard Deviation (PSD) scores between groups: Control, Health, and Therapy. The table shows the mean \pm standard deviation (SD).

\begin{tabular}{|c|c|c|c|c|}
\hline PSD score & $\begin{array}{c}\text { T0 } \\
\text { (mean } \pm \text { SD) }\end{array}$ & $\begin{array}{c}\text { T12 } \\
\text { (mean } \pm \text { SD) }\end{array}$ & $\begin{array}{c}\text { T24 } \\
\text { (mean } \pm \text { SD) }\end{array}$ & $\begin{array}{c}\text { T36 } \\
\text { (mean } \pm \text { SD) }\end{array}$ \\
\hline Control Group & $13 \pm 3.9$ & $13 \pm 4$ & $13 \pm 2.8$ & $13 \pm 3$ \\
\hline Healthy Group & $2 \pm 0.6$ & $2 \pm 0.1$ & $2 \pm 0.7$ \\
\hline Therapy Group & $13 \pm 3.2$ & $13 \pm 2.6$ & $12 \pm 4.2$ & $11 \pm 3$ \\
\hline
\end{tabular}


1 Table IV: Relative change in Pattern Standard Deviation (PSD) score in each group, as compared to

2

3 previous values. Student's t test for paired samples. (*). A p value > 0.05 is statistically significant.

\begin{tabular}{|c|c|c|c|c|c|c|}
\hline PSD & $\begin{array}{c}\text { T0- T12 } \\
(\Delta)\end{array}$ & p-value & $\begin{array}{c}\text { T0- T24 } \\
(\Delta)\end{array}$ & p-value & $\begin{array}{c}\text { T0- T36 } \\
(\Delta)\end{array}$ & p-value \\
\hline Control Group & $<1 \%$ & 0.654 & $<1 \%$ & 0.222 & $<1 \%$ & 0.151 \\
\hline Healthy Group & $<1 \%$ & 0.432 & $<1 \%$ & 0.272 & $<1 \%$ & 0.295 \\
\hline Therapy Group & $<1 \%$ & 0.234 & $-7 \%$ & 0.752 & $-16 \%$ & $0.001\left(^{*}\right)$ \\
\hline
\end{tabular}


1

2

3

4

5

6

7

8

10

11

12

13

14

15

16

17

18

19

20

21

22

23

24

25

26

27

28

29

30

31

32

33

34

35

36

37

38

39

40

41

42

43

44

45

46

47

48

49

50

51

52

53

54

55

Table V: GSS2 Stage comparison between groups: Control, Health, and Therapy. The table shows the mean \pm standard deviation $(S D)$.

\begin{tabular}{|c|c|c|c|c|}
\hline GSS2 Stage & $\begin{array}{c}\text { T0 } \\
\text { (mean } \pm \text { SD) }\end{array}$ & $\begin{array}{c}\text { T12 } \\
\text { (mean } \pm \text { SD) }\end{array}$ & $\begin{array}{c}\text { T24 } \\
\text { (mean } \pm \text { SD) }\end{array}$ & $\begin{array}{c}\text { T36 } \\
\text { (mean } \pm \text { SD) }\end{array}$ \\
\hline Control Group & $4 \pm 1.5$ & $4 \pm 1.6$ & $4 \pm 1.1$ & \\
\hline Healthy Group & 0 & 0 & 0 \\
\hline Therapy Group & $4.1 \pm 1.4$ & $3.4 \pm 1.3$ & $2.7 \pm 1.2$ & $3 \pm 1.3$ \\
\hline
\end{tabular}


6

7

8

10

11

12

13

14

15

16

17

18

19

20

21

22

23

24

25

26

27

28

29

30

31

32

33

34

35

36

37

38

39

40

41

42

43

44

45

46

47

48

49

50

51

52

53

54

55

Table VI: Relative percentage differences $(\Delta)$ between the times divided by groups. Student's $t$ test for paired samples. (*). A p value > 0.05 is statistically significant.

\begin{tabular}{|c|c|c|c|c|c|c|}
\hline GSS2 Stage & $\begin{array}{c}\text { T0- T12 } \\
(\boldsymbol{\Delta})\end{array}$ & p-value & $\begin{array}{c}\text { T0- T24 } \\
(\boldsymbol{\Delta})\end{array}$ & $\mathbf{p}$-value & $\begin{array}{c}\text { T0- T36 } \\
(\boldsymbol{\Delta})\end{array}$ & p-value \\
\hline Control Group & $<1 \%$ & 0.255 & $<1 \%$ & 0.512 & $+2 \%$ & 0.413 \\
\hline Healthy Group & $<1 \%$ & 0.125 & $<1 \%$ & 0.212 & $<1 \%$ & 0.313 \\
\hline $\begin{array}{c}\text { Therapy } \\
\text { Group }\end{array}$ & $-12.8 \%$ & 0.068 & $-30 \%$ & $\mathbf{0 . 0 0 1}(*)$ & $-35 \%$ & $\mathbf{0 . 0 0 1}(*)$ \\
\hline
\end{tabular}




\section{Figure legends}

Figure 1 -Mean Deviation (MD) trend as a function of time (Times 0, and 12, 24, and 36 months) and therapy.

Figure 2 - Pattern standard deviation (PSD) trend as a function of time (Times 0, and 12, 24, and 36 months) and therapy.

Figure 3 - Glaucoma Staging System 2 (GSS2) stage trend as a function of time (Times 0, and 12, 24 , and 36 months) and therapy.

Figure 4 -Best-corrected visual acuity (BVCA) as a function of time (Times 0, and 12, 24, and 36 months) and therapy.

Figure 5-Mean intraocular pressure (IOP) trend as a function of time (Times 0, and 12, 24, and 36 months) and therapy. 


\section{References}

1. Lee JWY, Chan PP, Zhang X, Chen LJ, Jonas JB. Latest Developments in Normal-Pressure Glaucoma: Diagnosis, Epidemiology, Genetics, Etiology, Causes and Mechanisms to Management. Asia Pac J Ophthalmol (Phila). 2019;8: 457-468.

2. Pacella E, Pacella F, Cavallotti C, Librando A, Feher J, Pecori-Giraldi J. The combination latanoprost-timolol versus twice daily $0.50 \%$ timolol administration either associated or not with latanoprost: efficacy and tolerability in the primary open-angle glaucoma. Eur Rev Med Pharmacol Sci. 2010;14: 477-480.

3. Pacella F, Turchetti P, Santamaria V, Impallara D, Smaldone G, Brillante C, et al. Differential activity and clinical utility of latanoprost in glaucoma and ocular hypertension. Clin Ophthalmol. 2012;6: 811-815.

4. Gandolfi S, Marchini G, Caporossi A, Scuderi G, Tomasso L, Brunoro A. Cytidine 5'Diphosphocholine (Citicoline): Evidence for a Neuroprotective Role in Glaucoma. Nutrients. 2020;12. doi:10.3390/nu12030793

5. Arrico L, Giannotti R, Fratipietro M, Malagola R. Fascicular Visual Fiend Defects in OpenAngle Glaucoma: Evaluation with Microperimetry.J Ophthalma1 2016;2016: 8274954. 
Page 16 of 21

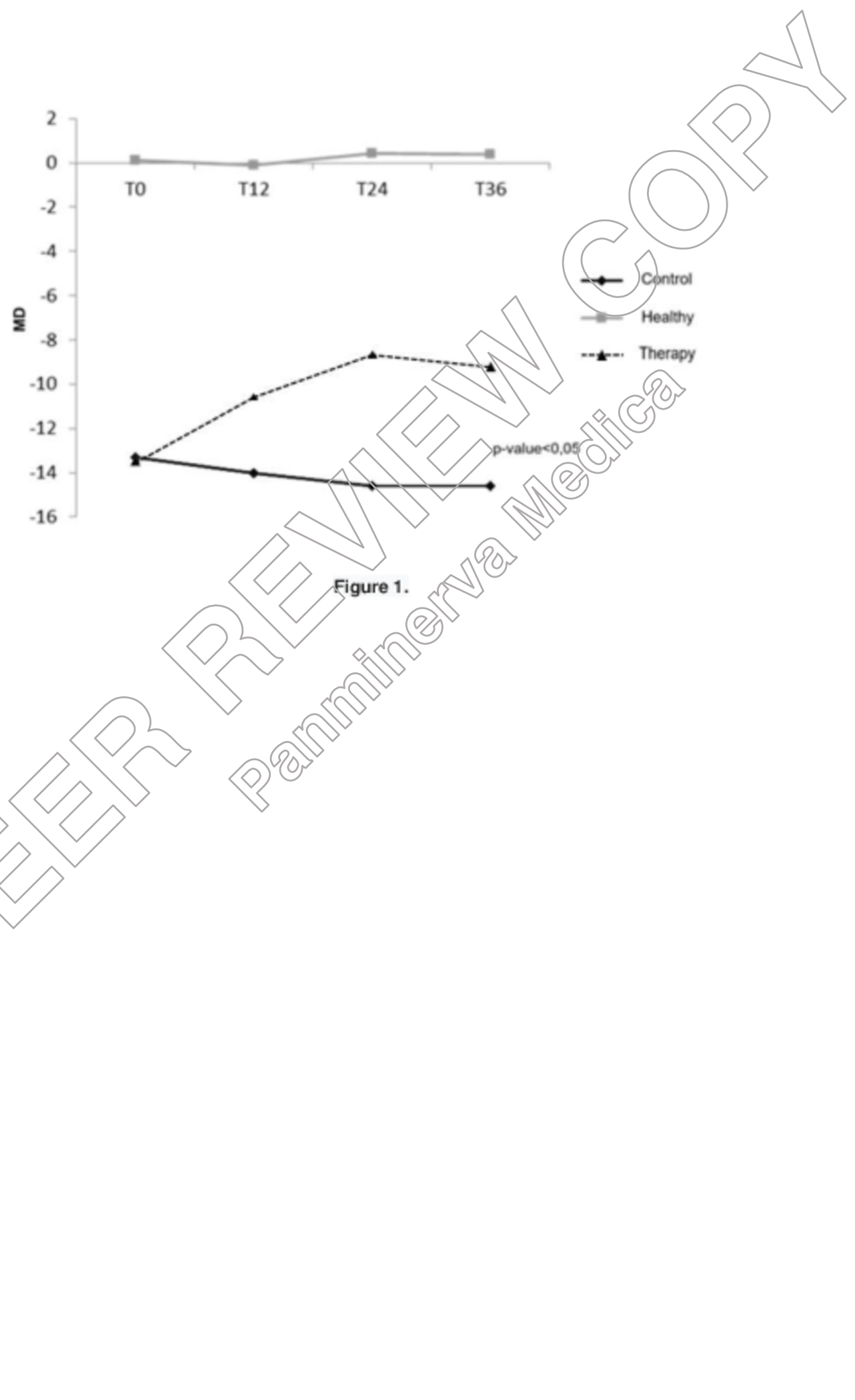




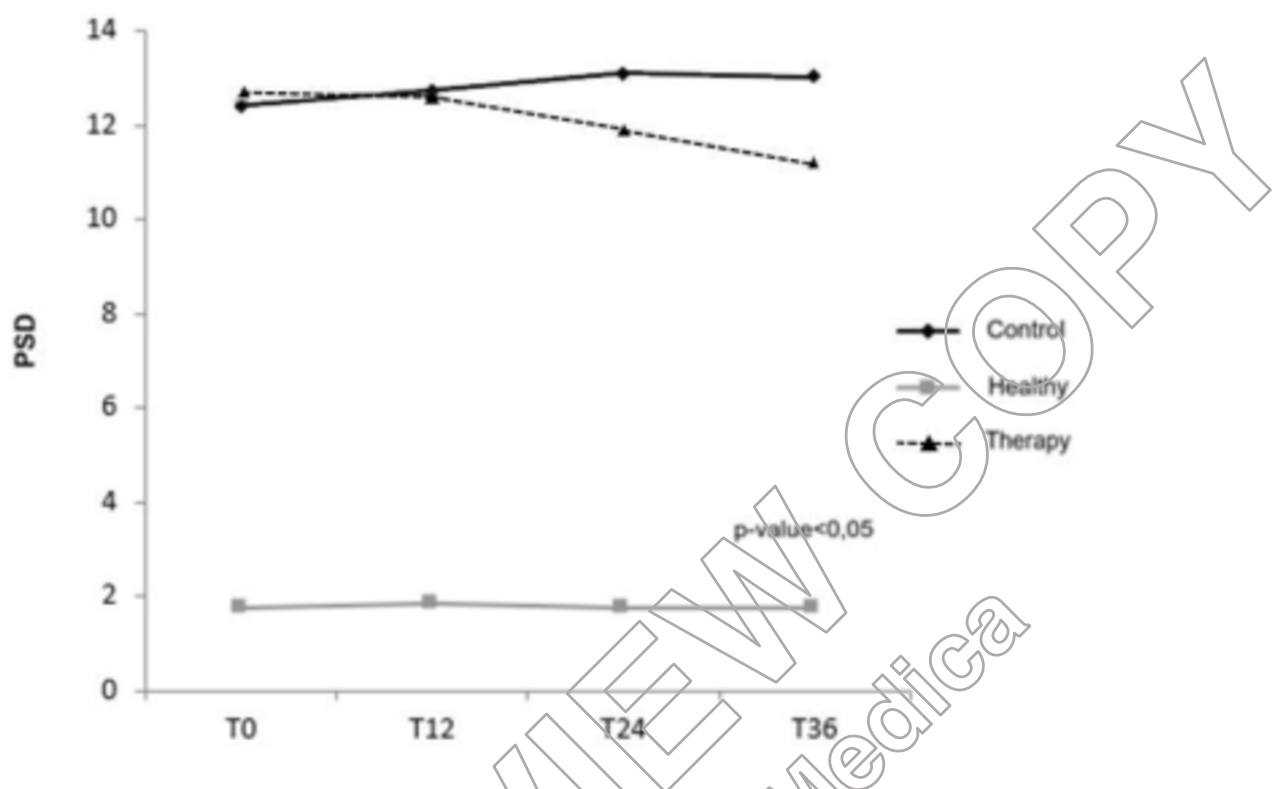

Figure 2.

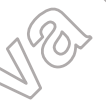


Page 18 of 21

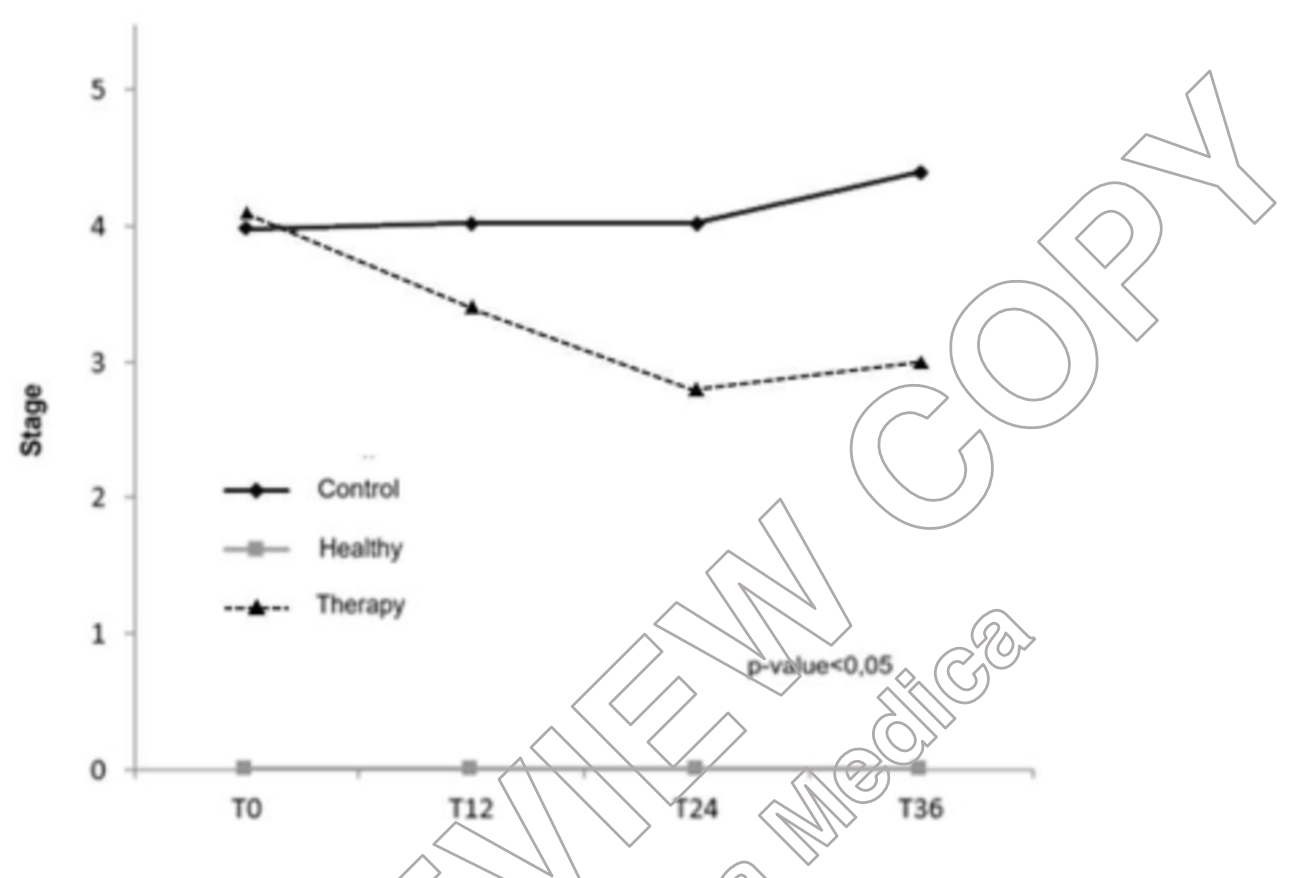

26

28

29

30

31

32

33

34

35

36

37

38

39

40

41

42

43

44

45

46

47

48

49

50

51

52

53

54

55 


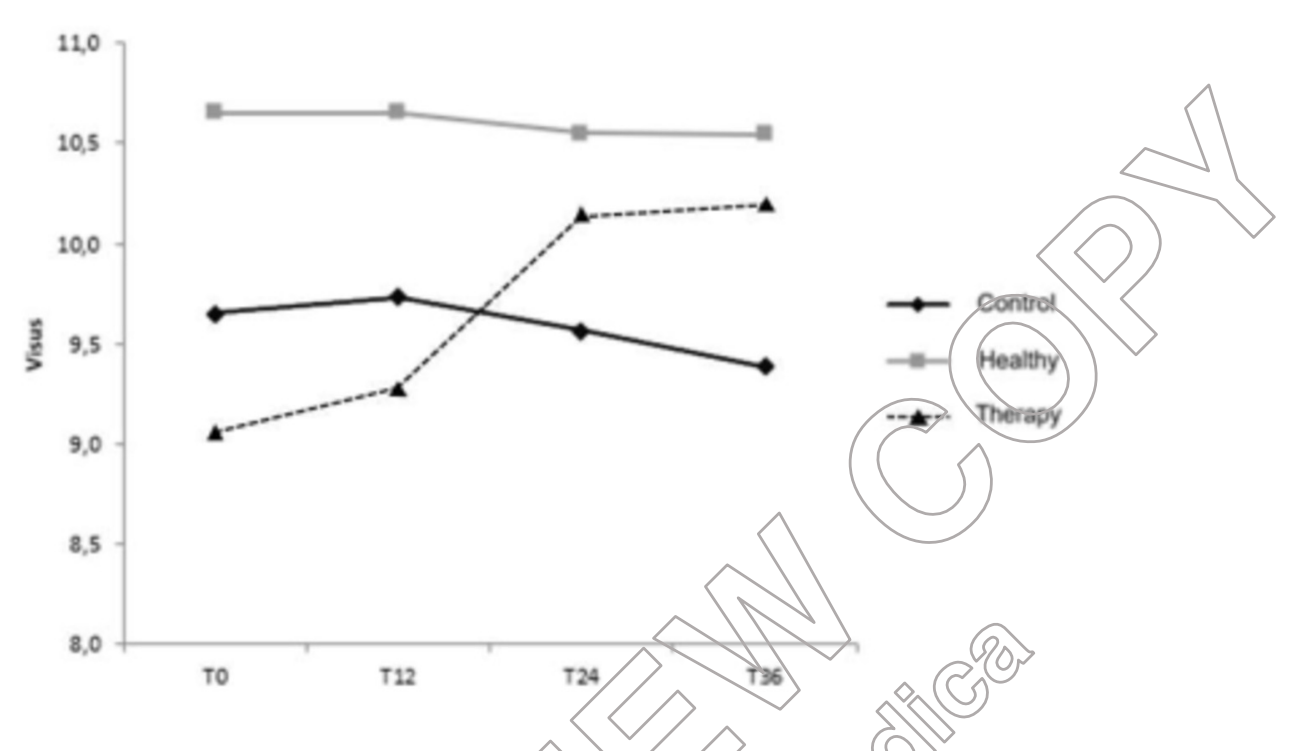




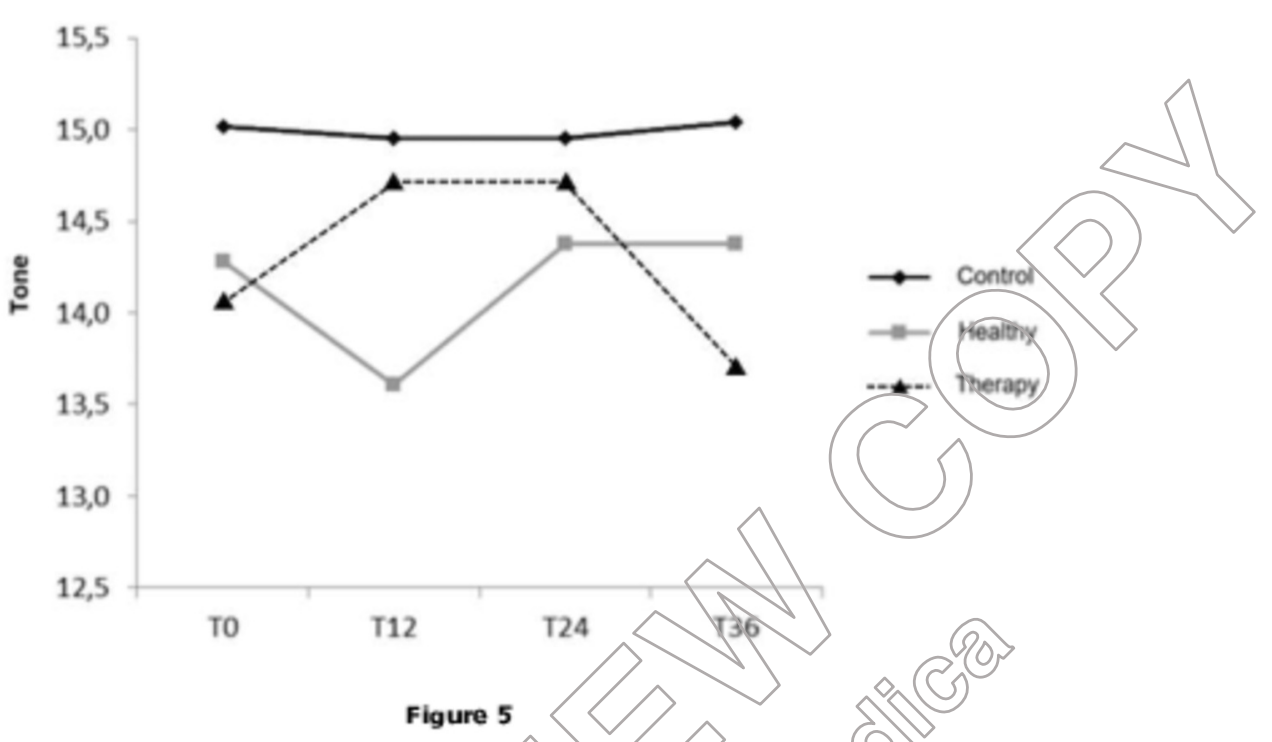

23

24

25

26

27

28

29

30

31

32

33

34

35

36

37

38

39

40

41

42

43

44

45

46

47

48

49

50

51

52

53

54

55 


\section{Supplementary Digital Material}

1

2

3

4

5

6

7

8

9

10

11

12

13

14

15

16

17

18

19

20

21

22

23

24

25

26

27

28

29

30

31

32

33

34

35

36

37

38

39

40

41

42

43

44

45

46

47

48

49

50

51

52

53

54

55

Download supplementary material file: Panminerva Med-4005 Supplementary Digital Material1_V1_2020-08-09.docx

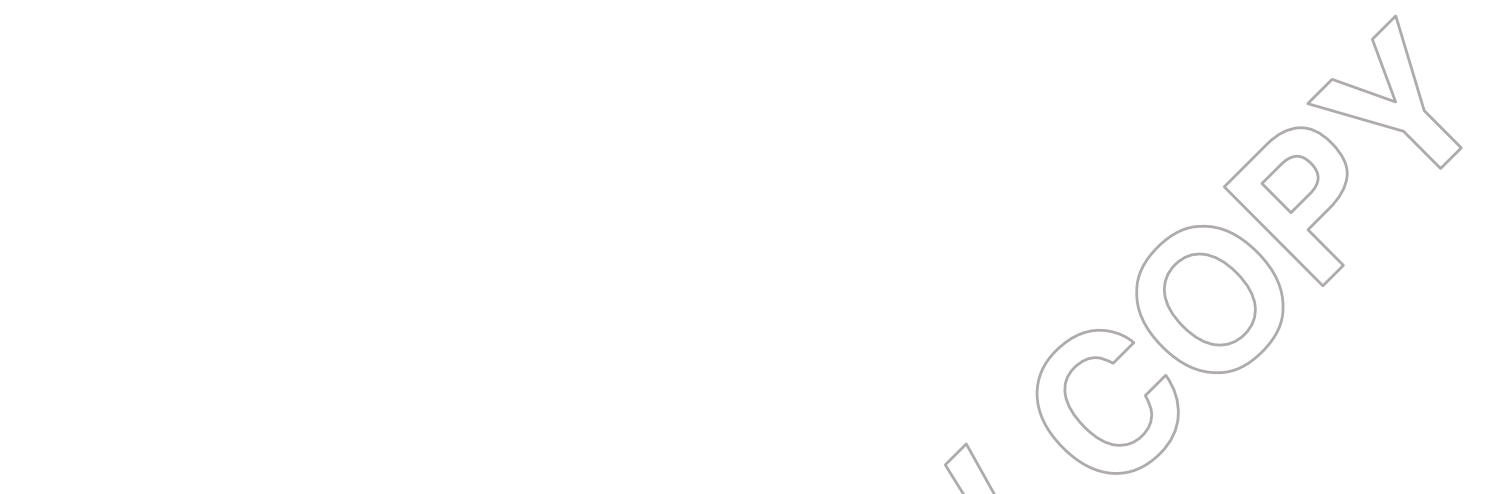

